\title{
Material Well-being and Happiness in Transition Countries
}

\author{
Marko Družić * \\ Martina Majstorovic ${ }^{* *}$
}

\begin{abstract}
The purpose of this paper is to further the research of the connection between material well-being and happiness in transition economies. We analyzed panel data obtained from the World Database of Happiness and Eurostat. Our results indicate that out of all the major macroeconomic variables (GDP, employment, inflation, taxes etc.), the most significant (and the only stable) predictor of changes in happiness in transition countries is the level of employment. The results are consistent with a hypothesis of a still prevalent "socialist mentality" in the analyzed sample of countries which are all formerly socialist economies that typically place high (or full) employment as the highest economic priority (as opposed to GDP growth, low inflation etc.). Our results differ from the conclusions of the few studies done on this sample of countries, which suggests additional research on the subject is likely required.
\end{abstract}

Keywords: GDP; unemployment; happiness; well-being; transition

JEL Classification: I, I3, I31

\section{Introduction}

The original empirical research on the relationship between material well-being and personal happiness asked a deceptively simple question: will raising the income of all increase the happiness of all? Today, more than 40 years later, that question still isn't unambiguously answered. Common sense would seem to suggest that the answer is yes; if people receive more money they could improve their quality of life and should therefore be happier. But, the data shows that the relationship between income and happiness isn't that simple. Furthermore, depending on the data and method used,

\footnotetext{
* Marko Družić is at the Faculty of Economics and Business Zagreb, University of Zagreb, Zagreb, Croatia.

** Martina Majstorović is at the University of Zagreb, Zagreb, Croatia
} 
quite different results can be obtained. Most empirical findings suggest that there is a significant positive correlation between a person's income and their happiness, but looking at that same correlation aggregately and through time led some researchers to quite different results. These results can be succinctly summarized under the famous "Easterlin paradox". The paradox, put forth by Easterlin (1974), states that although income and economic growth are important for a person's happiness, paradoxically in the long term, the variables do not seem to be connected.

Exploring this phenomenon led to different possibilities and theories concerning the question why economic growth won't raise the level of happiness in the longterm. For one, people are social beings, when evaluating their level of happiness they don't just look at their own life circumstances and conditions but also of the people around them. If surrounded with people who fare better than them they will be less happy than if they were surrounded with people who fare worse than them. Another thing to bear in mind is that people are adaptive. What was once a huge rise in income, over time becomes something normal and expected. People adapt to the new life standards as though the growth never happened. While these explanations focus on people and their assessment of their own happiness, some researchers looked for the answer to the paradox in economic growth itself considering the negative effects of economic growth, such as: pollution, inequality, crime and stress.

The purpose of this paper is to further the research of the connection between material well-being and happiness by using a relatively unexplored dataset: transition economies. The idea is to see what happens to the results when the stable environment of developed countries with relatively constant growth rates is replaced with the underperforming, sometimes chaotic economic and political environment of the transition countries. Our only predecessor which focused exclusively on transition economies is the paper by Malašević-Perović (2009) upon which we aim to build and expand.

\section{Literature Review}

The literature reviews of this subject usually begin with the work of Easterlin. Looking at the data for the last 50 years Easterlin (1974) concluded that although there was consistent economic growth in the USA, there was no increase in happiness. Further examining this phenomenon, he concluded that people in part judge their personal well-being by comparing their status with the status of people around them (Easterlin, 1995). So, although people received an economic boost and had better life circumstances, they were still on the same level relative to others.

On the other hand, there was evidence that richer individuals were happier than poorer ones. Di Tella, MaCulloch and Oswald (2003) looking at a random sample of Europeans and Americans from 1970s to 1990s found evidence of a positive and 
well-determined effect of GDP per capita on individual's perceived well-being, supporting the idea that an increase in national income is associated with higher reported happiness. Hagerty and Veenhoven (2003) included longer time series (1958-1996) and 21 countries divided into three groups: countries with high GDP/capita, medium GDP/capita and countries with real GDP/capita of less than $\$ 10,000$. They tested the theory of relative utility ${ }^{1}$ and the theory of absolute utility ${ }^{2}$ and came to similar findings.. "They concluded that increasing national income does go with increasing national happiness, consistent with a needs theory and contrary to strong relative utility models" (Hagerty and Veenhoven, 2003). Their research was later criticized for its data management and methodology. Easterlin (2005) stated that their findings were a result of mixing together two sets of non comparable surveys. He countered that if countries in their analysis with quite similar growth rates are grouped, one finds quite disparate trends in happiness, suggesting that other factors than growth in income are responsible for the differential trends of happiness.

Layard (2006) presented several possible explanations of the "Easterlin paradox". First, a person's happiness is negatively affected by the income of others, second, a person's happiness adapts quite rapidly to higher levels of income, and lastly the happiness we get from what we have is largely culturally determined. The first possible explanation is called social comparison, i.e. people compare their income with the income of others. In some studies the negative effect of average income is almost as large as the positive effect of larger personal income. The second explanation is simple human adaptation, having once experienced higher standard of living, a person cannot revert to what he/she had before and feel the same as he/she did then.

Stevenson and Wolfers (2008) revisited the findings and facts regarding the question of GDP and well-being. They analyzed the relationship through three channels: the difference between rich and poor members within countries, the difference between rich and poor countries and the path of average happiness as the average income of countries change. They stated that the contrast between the rich and the poor is similar to the contrast between the rich countries and the poor ones which is ultimately similar to the time-series relationship. The authors warn that the data on the time-series relationship is scarce, but that the general finding is that well-being increases during the time of economic growth. They state that however these findings have one exception, the USA data, where there is no notable growth of well-being despite economic development. These new findings led researchers to compare the correlation of GDP and well-being between cross-section and time-series datasets.

Easterlin and Angelescu (2009) found that there are two main conclusions that derive from the cross sectional analysis: if richer and poorer countries are compared at a point in time, life satisfaction increases with the absolute amount of GDP per capita, but at a diminishing rate. The second is that comparing richer and poorer countries at a point in time, each doubling of GDP is associated with a constant increase in life satisfaction. The difference from the first conclusion is that the change 
in life satisfaction is measured in relation to the proportionate, rather than absolute change in GDP, and life satisfaction is plotted against log GDP, not absolute GDP. Looking at the time series evidence they concluded that looking individually at the developed, developing and transition countries there is no significant relationship between the rate of improvement in life satisfaction and the growth rate of GDP per capita, also, for all countries taken together, there is no significant relationship. They stated that the disjunction between short and long-term relationship is the counterpart of the phenomena of "loss aversion", that the pain of losing is psychologically about twice as powerful as the pleasure of gaining, and so people are more willing to take risks in order to avoid a loss than to acquire a gain.

In an answer to continuing criticism of the "Easterlin paradox" Easterlin et. al. (2010) summarize and rebut the major critiques of the paradox. They state that the first one is based on the cross-section evidence of a positive happiness-income relationship and that in the economics of happiness literature this positive relationship has been well accepted for several decades. Secondly, some researchers suggest that the life satisfaction and happiness measures reflect different determinants, the former, economic conditions and the latter, political circumstances. As the third critique, based on the current findings in time series data, they state that what authors estimate as a long-term relationship is in fact a short-term relationship between life satisfaction and GDP.

Diener, Ng, Harter and Arora (2010) took one step further, exploring the reasons why happiness is associated with higher income looking at the meeting of basic needs and fulfillment of psychological needs. Looking at the representative surveys of 132 countries from 2005 to 2006 they found that income was positively associated with well-being and positive feeling and negatively associated with negative emotions but that income was much more strongly associated with well-being than with other measures. Overall, the authors found that income does have a stronger association with some types of well-being than with others and that the income and well-being correlations were fairly consistent across groups. Also, the relationship between income and life evaluations was slightly stronger in wealthy nations than in poor ones.

Clark and Senik (2011) summarized the current findings on the correlation of GDP and well-being. "Within-country surveys include individual income or household income as a control variable to explain well-being and it is typically one of the most important correlates of self-declared happiness" (Clark and Senik, 2011). This is true in both developed and developing countries. Cross-section research of countries shows that there exists a concave relationship between income per capita and average happiness across developed, developing and transition countries. Regarding the time-series findings, they found that the GDP growth goes with a series of quantitative and qualitative monetary improvements in quality of life. In accordance with these findings is also Veenhovens and Vergunsts (2013) paper named "The Easterlin illusion" in which they show that happiness tends to rise over time and raises more in 
nations where the economy grew most. Looking at the data from 67 nations ranging from 10 to more than 40 years they conclude that the long-term effect of economic growth on happiness is substantial and that it leads to a new agenda for research. The authors claim that though there are cases when happiness remains stable in spite of economic growth, that that's an exception rather than a rule.

Malašević Perović (2008) looked at the data for transitional countries in the years 1991, 1992, 1994 and 1998 and came to similar findings. Testing the importance of several macroeconomic variables for well-being in transition countries, the author concluded that the key macroeconomic variables of inflation, unemployment and GDP matter for the public's subjective economic well-being in transition countries. Improvement in national income leads to temporary and permanent gains in subjective economic well-being in transition countries. Individuals become accustomed to an increase in national growth, showing the signs of adaptation, but not all the benefits of this increase dissipate over time. Furthermore, the author found GDP growth and unemployment to be more important than inflation in transition countries.

\section{Data and Method}

If the goal is to explore the relationship between material well-being and happiness, measures of both must be available. Measures of material well-being (such as GDP, GDP per capita, employment etc.) are very familiar to the economist, as they constitute the basic building blocks of a majority of empirical work done in economics. On the other hand, the measurement of happiness is a completely different subject. Personal happiness cannot be observed, it is not measurable in the same sense that GDP is. This forced researchers to look for different methods of obtaining data other than direct measurement. It was decided that the best source of information of an individual's happiness is the individual himself, therefore research should proceed with individual surveys as the basic unit of analysis. These types of surveys usually involve questions such as "On a scale of 1 to 4 how satisfied are you with your life? (1 - dissatisfied, 2 - not very satisfied, 3 - fairly satisfied, 4 - very satisfied). Data gathered in this fashion is ordinal, it represents a preference ranking rather than an exact number (i.e. while 2 is bigger than 1 and 3 is bigger than 2 , we cannot say by how much). The result is a relatively rare problem in economics: ordinal data on the left side of the equation (happiness), and cardinal data on the right side (measures of material well-being).

In the vast majority of the existing literature, this specific character of the data led to the use of two primary research methods. The first involves using logit, probit, ordered logit and ordered probit methods, which are specifically designed for equations with ordinal dependent and cardinal independent variables. The other is to change the character of the data by using some method of averaging the ordinal results (in- 
stead of using each individual survey as a data point, the surveys are averaged to get an aggregate number), which then become cardinal and allow the use of standard econometric techniques (such as ordinary least squares and panel analysis).

We analyzed data for 8 transition European countries: Romania, Slovakia, Poland, Czech Republic, Croatia, Hungary, Bulgaria and Slovenia in the period from 2004 to 2015. We used data from the World Database of Happiness which represents a collection of scientific findings and research on subjective enjoyment of life. As a measure of happiness we focused on the question from the Eurobarometer survey "On the whole how satisfied are you with the life you lead?" (4-very satisfied, 3-fairly satisfied, 2-not very satisfied, 1-not at all satisfied, don't know). For the purpose of this research, we used converted data values on a scale from 1 to 10 , which were averaged to supply the aggregate mean value for each country in a specific year. Additionally, surveys were in some cases taken multiple times in the same year, which was resolved by taking the mean value between the surveys.

To measure economic well-being we decided on five main variables: GDP, employment, wages, taxes and inflation. The data for each was taken from the Eurostat database. We experimented with two measures of GDP: real GDP per capita GDP calculated as an index $(2010=100)$, and real GDP in absolute terms. For a measure of employment we used the ratio of employed persons and total population, wages were measured as a percentage of aggregate GDP, taxes were measured in index form $(2010=100)$, and inflation by the HICP index (Harmonized Index of Consumer Prices).

Two facts were crucial when deciding on the proper method of analysis. The first is that we use a measure of happiness that is continuous which allows the use of standard econometric techniques. The second is that our dataset is comprised of multiple countries. Taken together they strongly suggest panel analysis as the most appropriate method. Our equation is as follows:

$$
H_{j t}=\alpha+G D P_{j t}+W_{j t}+E M P_{j t}+H I C P_{j t}+T_{j t}+\varepsilon_{j t}
$$

"H" represents happiness, "GDP" represents GDP, "W" represents wages, "EMP" represents employment, "HICP" is the inflation index, and "T" represents taxes, while " $\mathrm{j}$ " is the country index, and " $\mathrm{t}$ " the time (year) index. We test the standard three models of static panel analysis: pooled OLS, fixed and random effect models. In our opinion, this should constitute a small improvement upon previous research discussed in the literature review, which usually focused primarily on simple OLS. Furthermore, our analysis should shed some additional light on the situation in transition countries, since the main paper we are aware of that deals with that specific problem is the paper by Malašević-Perović, which uses a substantially smaller sample of years (four instead of eleven used in this paper), and a different method (logit and ordered probit as opposed to panel analysis). 


\section{Results}

\section{Descriptive Statistics}

Average happiness per country is shown in Figure 1. Most of the countries in our sample are placed between the values 4 and 6 indicating average life satisfaction. Slovenia stands out with the highest life satisfaction result for the tested period while the lowest life satisfaction is measured in Bulgaria. All in all, we can see that although there are some minor variations in life satisfaction through the years, general happiness per country is stable with a slight growth in the period since 2013.

Figure 1: Average happiness per country 2004-2015

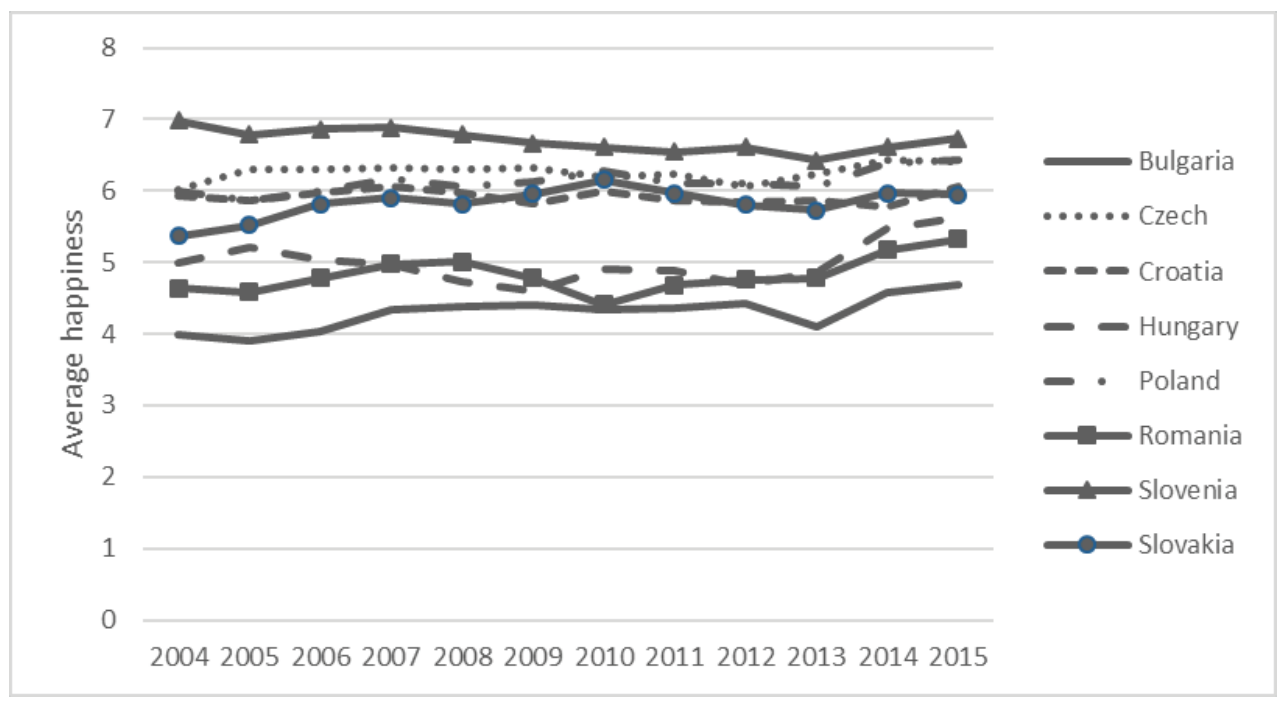

Source: Eurostat

In the following figure we can see GDP values per country (Figure 2). All countries show positive growth rates with until the recession in 2008, when naturally GDP levels drop in every country in the sample. Poland exhibits the fastest recovery rate with strong GDP growth beginning again in 2010, while the rest of the countries in the sample experience a very slow recovery with minimal growth rates. 
Figure 2: GDP per country 2004-2015

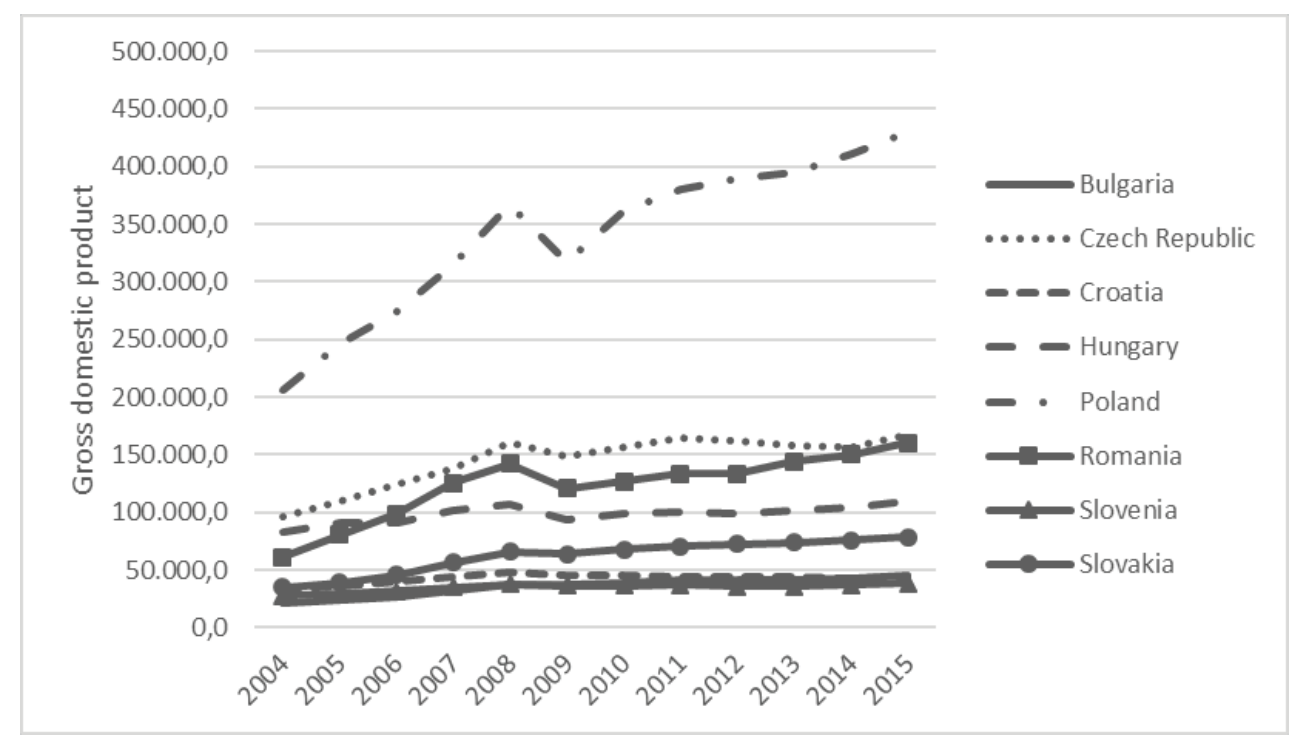

Source: Eurostat

Figure 3 shows the unemployment rates of each country in the sample. Most countries show a similar pattern, a fall in unemployment leading to 2008 after which follows a period of higher unemployment that stabilizes around 2013. The Czech Republic, Romania and Hungary have the lowest unemployment rates (4,4\%-11.3\%). After 2008 we can see that Croatia has the highest unemployment rate (17.5\% in 2013 and 2014), followed by Slovakia and Bulgaria.

With the naked eye there seems to be no causal connection between happiness and these two economic indicators. Both unemployment and GDP levels experience a reverse trend after 2008, with no such trend visible in the happiness statistics. 
Figure 3: Unemployment rates per country 2004-2015

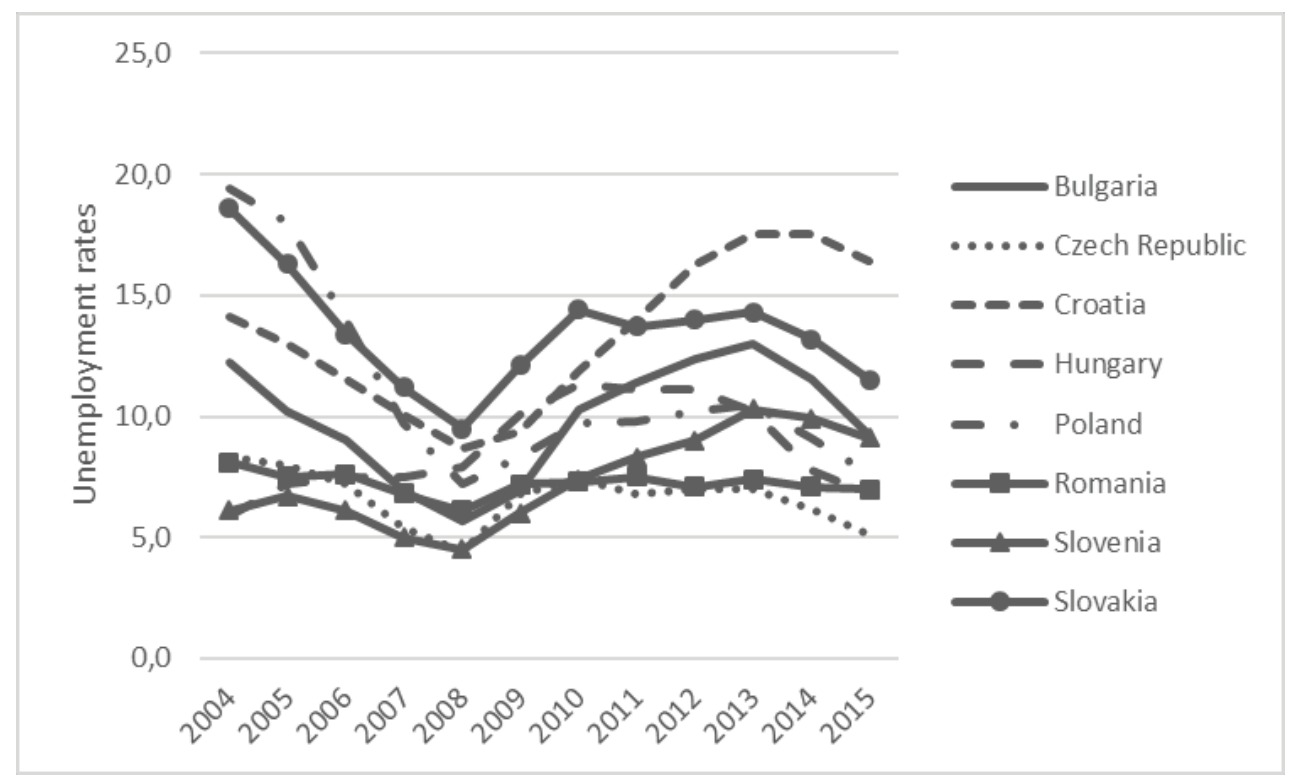

Source: Eurostat

\section{Panel Analysis}

We experimented with a large number of variations on equation (1). Log-log, in addition to log-linear and linear-log forms were analyzed, as well as different measures of GDP (in absolute and index form). Additionally, since there is good reason to assume that some of the independent variables are correlated to some degree (employment and wages, GDP and employment etc.) we ran various alternative specifications which involved removing and adding all such variables to see whether the fundamental results change.

What we consider as representative results (log-log specification with real GDP per capita as the GDP measure) is given in Table 1. 
Table 1: Results of the panel analysis

\begin{tabular}{|c|c|c|c|}
\hline & \multicolumn{3}{|c|}{ Dependent variable: } \\
\hline & \multicolumn{3}{|c|}{ Happiness } \\
\hline & OLS model & Random model & Fixed model \\
\hline \multirow[t]{2}{*}{ Constant } & $1.203^{*}$ & -0.645 & \\
\hline & $(0.682)$ & $(0.554)$ & \\
\hline \multirow[t]{2}{*}{ GDPpc } & $0.279^{* * *}$ & $0.152^{* * * *}$ & $0.097^{*}$ \\
\hline & $(0.029)$ & $(0.043)$ & $(0.051)$ \\
\hline \multirow[t]{2}{*}{ Taxes } & $-0.470^{* * * *}$ & $-0.163^{*}$ & -0.081 \\
\hline & $(0.124)$ & $(0.096)$ & $(0.104)$ \\
\hline \multirow[t]{2}{*}{ Wages } & -0.001 & 0.063 & 0.061 \\
\hline & $(0.061)$ & $(0.087)$ & $(0.094)$ \\
\hline \multirow[t]{2}{*}{ Inflation index } & -0.092 & $-0.111^{*}$ & -0.057 \\
\hline & $(0.084)$ & $(0.062)$ & $(0.068)$ \\
\hline \multirow[t]{2}{*}{ Employment } & 0.132 & $0.488^{* * * *}$ & $0.480^{* * * *}$ \\
\hline & $(0.152)$ & $(0.153)$ & $(0.157)$ \\
\hline \multirow[t]{2}{*}{ Constant } & $1.203^{*}$ & -0.645 & \\
\hline & $(0.682)$ & $(0.554)$ & \\
\hline Observations & 95 & 95 & 95 \\
\hline $\mathbf{R}^{2}$ & 0.737 & 0.381 & 0.322 \\
\hline Adjusted R ${ }^{2}$ & 0.722 & 0.347 & 0.223 \\
\hline F Statistic & $49.836^{* * *}(\mathrm{df}=5 ; 89)$ & $10.964^{* * *}(\mathrm{df}=5 ; 89)$ & $7.802^{* * *}(\mathrm{df}=5 ; 82)$ \\
\hline Note: & \multicolumn{3}{|c|}{$\mathrm{p}<0.1 ;{ }^{* *} \mathrm{p}<0.05 ;{ }^{* * *} \mathrm{p}<0.01$} \\
\hline
\end{tabular}

Source: Authors

OLS at first glance gives interesting results. The "GDPpc" and "Taxes" variables are significant at the $1 \%$ level, while the other variables are not significant. Furthermore, the signs of the variables are all as expected (even of variables which seem to be statistically not significant). GDPpc and the level of employment seem to have a positive effect on happiness, while taxes and inflation have a negative effect on happiness. The only anomalous result is the wage level which shows a slightly negative effect on happiness. Wages are also the only variable whose sign changes as different models are introduced (random, fixed).

The situation is different with the random and fixed models. The main difference is that the effect of taxes become substantially less significant (in magnitude as well as statistical significance) and the employment level becomes a deciding factor in the random and fixed effects models. To test which model is the most appropriate, we used the Breusch-Pagan version of the Lagrange multiplier test, and the Hausman test, with additional tests for heteroskedasticity and serial correlation ${ }^{3}$. The tests conclusively show that of the three, the fixed effects model is the most correct specification.

GDP, while barely significant in the results shown in Table 1, becomes insignificant in about half of the attempted alternative specifications, and becomes insignif- 
icant if the index form of the variable is introduced instead of the absolute variable form. In over $90 \%$ of alternative specifications, wages, inflation and taxes do not have a significant effect on happiness. Our only robust finding, through all the different attempted model variations and out of all the tested economic variables, is that the most significant (and the only stable) predictor of changes in happiness in transition countries is the level of employment.

\section{Conclusion}

The obtained results point to an interesting conclusion considering the political and cultural context which the countries in the sample share. They are all formerly socialist economies, which typically placed high (or full) employment as the highest economic priority (as opposed to GDP growth, low inflation etc.). This led to a very inflexible job market, firing employees was very difficult as it was contrary to the ideological foundations of the governing system. Once employed, individuals could in a vast majority of cases be reasonably confident that they would achieve retirement status in the same firm (if not on the same desk) that they started their career in. Individuals therefore were incentivized to consider employment as the only relevant factor when planning their economic future, since the last thing a socialist government can afford to do is to start laying off workers. This situation was further exasperated by the fact that by the 1980s, a number of the countries in the sample experienced relatively high levels of unemployment, which was somewhat alleviated by large numbers of workers starting to move abroad.

The results shown in Table 1 would seem to point to the conclusion that the above mentioned "socialist mentality" is still prevalent in the analyzed sample of countries, even 25 years after the process of transition to market economies. The other explanation that comes to mind is that the countries in the sample on average exhibit relatively high levels of unemployment, and that this fact by itself explains the econometric results, without the need to involve politics and mentality. However, these two explanations are not mutually exclusive, in fact one could very well be reinforcing the other.

Additionally, these results stand in contrast to the work done by MalaševićPerović $^{4}$, which concluded that GDP, unemployment and inflation all have a significant effect on happiness, and that unemployment and GDP have a larger effect on happiness than inflation. 


\section{NOTES}

${ }^{1}$ Which holds that people's happiness depends on a person's income relative to others (social comparison) or on income relative to their own past income (adaptive expectations).

${ }^{2}$ That predicts that additional income allows each person to fill additional needs, thus increasing average long-term happiness.

${ }^{3}$ The test results are not included in the paper, but are available upon request.

${ }^{4}$ It should be noted that the results are not altogether comparable, since different datasets and research methods were used.

\section{REFERENCES}

Clark, A., \& Senik, C. (2011). Will GDP Growth Increase Happiness in Developing Countries? (SSRN Scholarly Paper No. ID 1796590). Rochester, NY: Social Science Research Network.

Database - Eurostat. (n.d.). Retrieved May 22, 2017, from http://ec.europa.eu/eurostat/data/database

Diener, E., Ng, W., Harter, J., \& Arora, R. (2010). Wealth and happiness across the world: material prosperity predicts life evaluation, whereas psychosocial prosperity predicts positive feeling. Journal of Personality and Social Psychology, 99(1), 52-61.

Di Tella, R., MacCulloch, R. J., \& Oswald, A. J. (2003). The Macroeconomics of Happiness. The Review of Economics and Statistics, 85(4), 809-827.

Easterlin, R. (1974) Does Economic Growth Improve the Human Lot? Some Empirical Evidence" In: David, R. and Reder, R., eds. Nations and Households in Economic Growth: Essays in Honor of Moses Abramovitz, Academic Press, New York. - References - Scientific Research Publish. (n.d.).

Easterlin, R. A. (1995). Will raising the incomes of all increase the happiness of all? Journal of Economic Behavior \& Organization, 27(1), 35-47.

Easterlin, R. A. (2005). Feeding the Illusion of Growth and Happiness: A Reply to Hagerty and Veenhoven. Social Indicators Research, 74(3), 429-443.

Easterlin, R. A., \& Angelescu McVey, L. (2009). Happiness and Growth the World Over: Time Series Evidence on the Happiness-Income Paradox (IZA Discussion Paper No. 4060). Institute for the Study of Labor (IZA).

Easterlin, R. A., McVey, L. A., Switek, M., Sawangfa, O., \& Zweig, J. S. (2010). The happiness-income paradox revisited. Proceedings of the National Academy of Sciences, 107(52), 22463-22468.

Hagerty, M. R., \& Veenhoven, R. (2003). Wealth and Happiness Revisited - Growing National Income Does Go with Greater Happiness. Social Indicators Research, 64(1), 1-27.

Happiness in Nations. (n.d.). Retrieved May 22, 2017, from http://worlddatabaseofhappiness.eur.nl/ hap_nat/nat_fp.php

Layard, R. (2006). Happiness and Public Policy: A Challenge to the Profession*. The Economic Journal, 116(510), C24-C33.

Malešević Perović, L. (2009). Subjective Economic Well-being in Transition Countries: Investigating the Relative Importance of Macroeconomic Variables. Financial Theory and Practice, 32(4), 519-537.

Stevenson, B., \& Wolfers, J. (2008). Economic Growth and Subjective Well-Being: Reassessing the Easterlin Paradox (Working Paper No. 14282). National Bureau of Economic Research.

Veenhoven, R., \& Vergunst, F. (2013). The Easterlin illusion: economic growth does go with greater happiness (MPRA Paper No. 43983). University Library of Munich, Germany. 